\title{
Functional homogenization of bumblebee communities in alpine landscapes under projected climate change
}

\author{
Jean-Nicolas Pradervand ${ }^{1 \dagger}$, Loïc Pellissier ${ }^{2^{*}+}$, Christophe F Randin ${ }^{3}$ and Antoine Guisan ${ }^{1,4}$
}

\begin{abstract}
Background: Bumblebees represent an active pollinator group in mountain regions and assure the pollination of many different plant species from low to high elevations. Plant-pollinator interactions are mediated by functional traits. Shift in bumblebee functional structure under climate change may impact plant-pollinator interactions in mountains. Here, we estimated bumblebee upward shift in elevation, community turnover, and change in functional structure under climate change.

Method: We sampled bumblebee species at 149 sites along the elevation gradient. We used stacked species distribution models (S-SDMs) forecasted under three climate change scenarios (A2, A1B, RCP3PD) to model the potential distribution of the Bombus species. Furthermore, we used species proboscis length measurements to assess the functional change in bumblebee assemblages along the elevation gradient.

Results: We found species-specific response of bumblebee species to climate change. Species differed in their predicted rate of range contraction and expansion. Losers were mainly species currently restricted to high elevation. Under the most severe climate change scenarios (A2), we found a homogenization of proboscis length structure in bumblebee communities along the elevation gradient through the upward colonization of high elevation by species with longer proboscides.

Conclusions: Here, we show that in addition to causing the shift in the distribution of bumblebee species, climate change may impact the functional structure of communities. The colonization of high elevation areas by bumblebee species with long proboscides may modify the structure of plant-pollination interaction networks by increasing the diversity of pollination services at high elevation.
\end{abstract}

Keywords: Bombus, Species distribution models, Uncertainty, Climate change, Flower visitor, Insect

\section{Background}

Climate change has affected distribution and phenology of a wide range of taxa [1] and is forecasted to cause high rates of species extinctions [2]. In order to track climate change, species are expected to shift their range toward higher latitudes and elevations. Considering these movements, species-specific responses to climate change have the potential to create temporal or spatial mismatch between interacting species [3-5]. Due to biotic interdependences within trophic networks, loss or addition

\footnotetext{
* Correspondence: loic.pellissier@unifr.ch

${ }^{\dagger}$ Equal contributors

${ }^{2}$ Department of Biology Ecology \& Evolution, University of Fribourg, $\mathrm{CH}-1700$ Fribourg, Switzerland

Full list of author information is available at the end of the article
}

of species in local plant and animal assemblages may cause cascading changes [6,7]. Studies forecasting the effect of climate change on species turnover within communities generally overlook the potential effect of biotic interactions that link species fate to each other $[8,9]$. Hence, the consideration of the effect of species interactions represents a significant challenge for forecasting the future consequences of climate change [9,10]. A first step to understand how interactions may change in a warmer future is to investigate shift in the functional structure of communities [11].

Pollination is a key ecosystem service and an essential component for the maintenance of biodiversity in ecosystems [12]. From the coevolution of pollinator and 
flowering plant, intricate mutualistic networks emerged within communities [13]. Functional complementarity suggests that a higher diversity of pollinators contributes to increased pollination success of the plants or, in turn, that a higher diversity of flowers may better sustain a diverse guild of pollinators [14]. However, climate change is expected to affect the co-occurrences of plant and pollinator species in space due to climate tracking or local extinction and thus disrupt such networks. Species-specific range shift of plants [15] and pollinators [16-20] suggests that distribution overlaps between plants and pollinators will not remain the same in the future [21]. In contrast to highly specialized plant species (e.g., [22]), the pollination success of a vast majority of plant species is determined by the availability of a functionally appropriate flower visitor, with adequate features such as body size or proboscis length $[23,24]$. The floral morphologies in plant communities are thus tightly linked to the functional structure of the available pollinators through complementarity [14,25-27]. In this context, Lavorel et al. [28] suggested that the effect of climate change on pollinator communities might affect the frequency of functional groups in communities more than composition per se and that this will drive change in plant community structure.

Among the world's ecosystems, mountains and their unique biota are predicted to be disproportionally exposed to climate change with potential shifts in communities functional structure $[8,29,30]$. Bumblebees are the most efficient and active pollinators in alpine ecosystems [31], due to their capacity to generate heat [32] and fly over long distances [33]. Studying shift in bumblebee communities and functional structure informs on future plant-pollinator interaction in mountains. Bumblebees have evolved functional characters, like abundant hairs or muscles generating heat prior to flying enabling them to forage in cold environments [34,35]. These adaptations to cold make them potentially more sensitive to climate change. They also display proboscis of varying length which mediates the type of flowers they interact with [36]. Bumblebees with longer proboscides visit deeper flowers than those with short proboscides [36], but long-tongued species are currently restricted to lower elevation [37]. Climate change may greatly disrupt the established structure of plant-pollinator interactions through change in the proboscides of available pollinator in communities.

Stacked species distribution models (S-SDMs) allow assessing the potential impact of climate change on biological communities [38,39]. SDMs relate field occurrences to a series of environmental variables, in order to model a species realized environmental niche and its associated potential distribution in the landscape. S-SDMs then assemble communities issued from individual SDM predictions [40,41]. Maps issued from SDMs are often binarized using threshold values based on different optimization techniques maximizing for instance sensitivity and specificity (reciever operating characteristic (ROC), see Elith et al. [42] for more information), enabling the conversion of probabilities into binary maps. An alternative is to use resampling from probabilities using a binomial distribution [41]. This probabilistic approach allows modeling realized endpoint of assembly (i.e., one possible assemblage out of other possible ones) accounting for stochasticity $[39,41]$ may also account for uncertainty in the modelled response curves $[38,41]$.

Here, we used high-resolution environmental maps of proximal environmental predictors derived from weather stations, three IPCC-based climate change scenarios, and a novel probabilistic ensemble S-SDM approach to assess comprehensively the possible effect of climate change on the structure of communities of an entire regional bumblebee pollinator fauna by the end of the 21st century (2070-2099 time period average). More specifically, 1) to assess the potential consequence of climate change on species and communities, we estimated the percentage of suitable habitat loss for each species compared to the current distribution of suitable habitats. 2) We compared the current functional structure of bumblebee communities with regard to average proboscis length, with the forecasted future communities under climate change.

\section{Results}

\section{Overall diversity}

During the summers of 2009 and 2010, we sampled and identified 2,020 individuals across 149 sites, resulting in a total of 30 bumblebee species in the study area. The species from the Bombus sensu stricto subgenus occurring in the area (B. terrestris, B. lucorum, and B. cryptarum) have very similar workers, and identification of these workers to the species level can prove difficult for older individuals [43]. To avoid modeling bias resulting from poor taxonomic differentiation, we did not consider this group in further analyses. The Psithyrus subgenus (eight species) was also removed from the analysis as they parasitize the other Bombus species and are not frequent pollinators as they do not produce workers. Finally, five species-B. alpinus, B. gerstaeckeri, B. jonellus, $B$. subterraneus, and $B$. veteranus - had a too low number of occurrences (minimal number of occurrences needed = 15) to model their distributions.

\section{SDM predictive power and community evaluation}

The average area under the curve (AUC) value across all models ranged from 0.53 to 0.89 (average $=0.7$, Table 1 ). For each species and from the 20 repetitions of model runs, the ensemble forecasting method conserved only the models with AUC values above 0.7, keeping only the 


\begin{tabular}{|c|c|c|c|c|}
\hline Species & GLM & RF & GAM & Mean AUC \\
\hline B. hortorum & 0.676 & 0.570 & 0.394 & 0.546 \\
\hline B. humilis & 0.891 & 0.801 & 0.764 & 0.819 \\
\hline B. hypnorum & 0.930 & 0.676 & 0.621 & 0.743 \\
\hline B. lapidarius & 0.754 & 0.691 & 0.677 & 0.707 \\
\hline B. mendax & 0.776 & 0.704 & 0.664 & 0.715 \\
\hline B. mesomelas & 0.892 & 0.672 & 0.703 & 0.756 \\
\hline B. monticola & 0.759 & 0.686 & 0.625 & 0.690 \\
\hline B. mucidus & 0.834 & 0.754 & 0.507 & 0.699 \\
\hline B. pascuorum & 0.903 & 0.882 & 0.861 & 0.882 \\
\hline B. pratorum & 0.693 & 0.570 & 0.641 & 0.635 \\
\hline B. pyrenaeus & 0.854 & 0.800 & 0.808 & 0.821 \\
\hline B. ruderarius & 0.747 & 0.668 & 0.692 & 0.702 \\
\hline B. sichelii & 0.837 & 0.722 & 0.676 & 0.745 \\
\hline B. soroeensis & 0.569 & 0.429 & 0.422 & 0.473 \\
\hline B. wurfleinii & 0.743 & 0.571 & 0.629 & 0.647 \\
\hline
\end{tabular}

models with sufficient predictive power to be used for projections following the recommendation of the biomod2 package [44]. The prediction success of bumblebee communities (success of predicting the right species in right places) ranged from $0.37 \%$ to $0.62 \%$ and was the lowest at middle elevation corresponding to where communities have the highest species richness [37], thus where the species pool is also larger (Figure 1).

\section{Species loss under climate change}

No species was projected to lose $100 \%$ of its suitable habitat by 2085 for any scenario, but some species were forecasted to suffer a drastic reduction of their range. In particular, the species that occupy the coldest environment at high elevation are projected to lose more than $80 \%$ of their occupied range - B. sichelii $(-92 \%)$ and B. pyrenaeus (-96\%), B. mucidus (-83\%), B. mesomelas (-91\%), and B. mendax (-90\%) - under the most extreme A2 scenario (Table 2). The loss is roughly similar between scenarios except for RCP3PD with limited range loss for those species (Table 2). In contrast, several species are forecasted to increase the size of potentially suitable habitat. This is especially the case for three species from the warm-adapted subgenus Thoracobombus, B. pascuorum (+97\%), B. hortorum $(+30 \%)$, and B. hypnorum $(+405 \%)$. Overall, some groups were predicted to suffer greater loss of potential surfaces compared to other. The short-tongued clade Pyrobombus + Rhodobombus + Kallobombus is forecasted to lose a higher proportion of habitat surface (B. lapidarius and B. hypnorum excepted) compared to the long-tongued clade Thoracobombus + Megabombus, which tends to maintain its current range size with the exception of B. mucidus.

\section{Functional structure under climate change}

Under all climate change scenarios except the milder RCP3PD, the S-SDMs suggest an increase of the mean proboscis length in communities at high elevation, attenuating the current decrease in mean proboscis length along elevation (Figures 2 and 3). In a warmer future, bumblebee communities at the highest elevations will be more species rich and are expected to be composed of species with longer proboscides, currently restricted to lower elevation (Figure 1). Fewer differences in pollinator functional structure should be observed between lowland and high elevations at least with regard to bumblebees (Figure 4, for the variance in the 3 scenarios see Additional file 1: Figure S1).

\section{Discussion}

Bumblebees have evolved functional characters that allow them not only to tolerate cold temperatures but to show optimal efficiency at high elevations [45]. This specialization to cold environmental conditions should in turn render them more sensitive to climate change. Our results indicate that in the western Swiss Alps at least five bumblebee species could lose more than $80 \%$ of their range by 2085 and will risk local extinction if warming continues. This is particularly the case of some high-elevation specialist species like B. monticola, B. sichelii, and B. pyrenaeus which are potentially not tolerant to high temperature stress or are less efficient compared to more competitive bumblebee species occupying warmer conditions [46]. Our forecasted shift in elevation range of bumblebee species parallels results of a recent colonization of northern Europe by bumblebee species linked to climate change [47]. In addition, we showed that under climate change species with longer proboscides will be able to colonize higher elevation. In turn, the average and variance in proboscis length in higher elevation communities will increase potentially affecting plant-pollinator interactions for instance by reducing pollination limitation at high elevation [48].

\section{Species gain and loss under climate change}

The tolerance to climatic conditions is phylogenetically conserved in bumblebees [37]. One clade exhibits tolerances toward much lower temperature compared to its sister group. The present study indicates that species from the short proboscis group occurring overall at higher elevation will suffer a higher loss of occupied surfaces compared to species with a longer proboscis. Some groups such as the Thoracobombus (B. humilis, B. pascuorum, $B$. ruderarius) clade may even increase their occupied range under climate change. Even if some species show a decrease of more than $90 \%$ of their range, no 


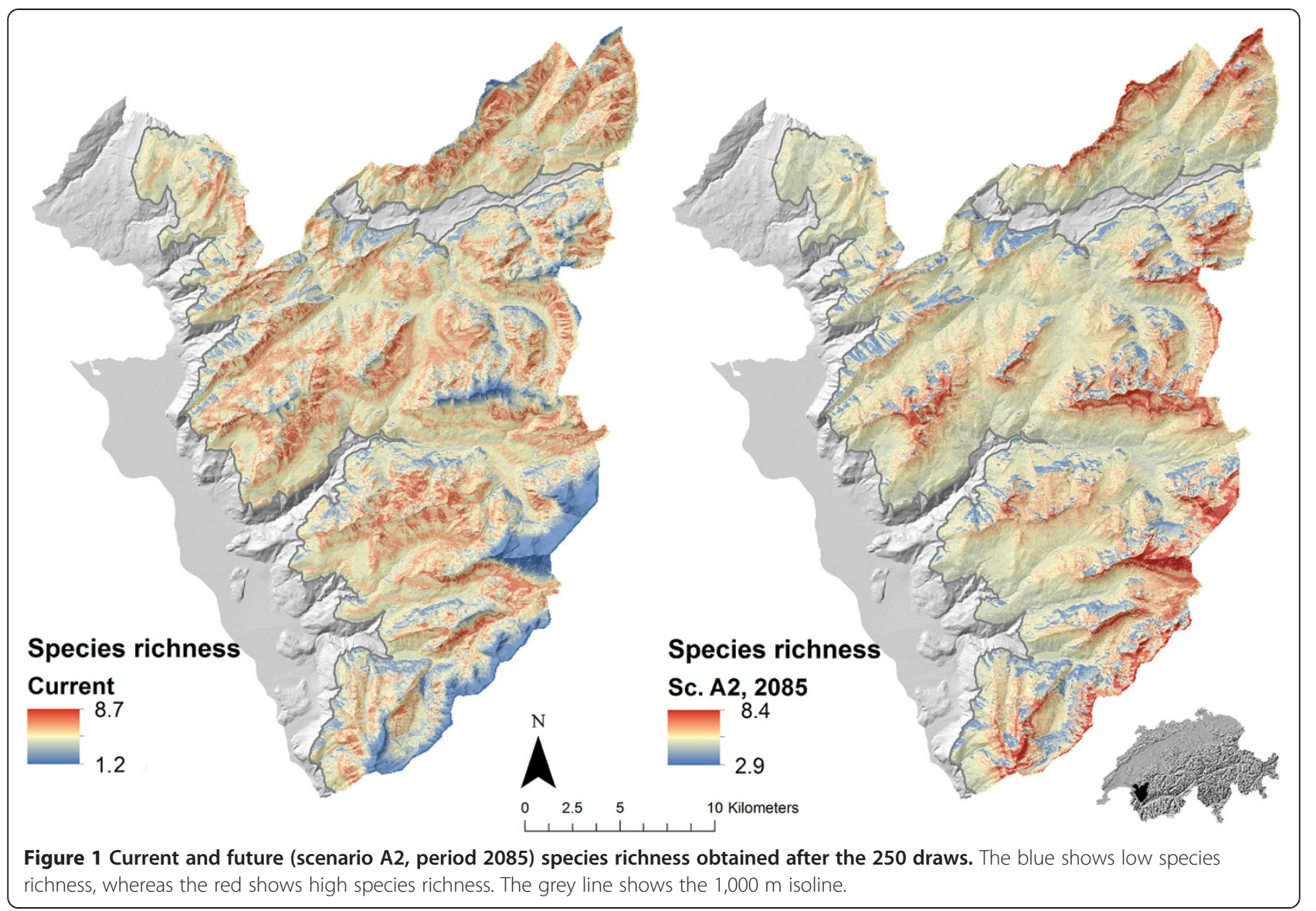

Table 2 Percentage of future to current occupied surfaces for all the species and the 15 bumblebee species individually represented following the three scenarios

\begin{tabular}{lllllllllllll}
\hline & A2 & A1B & RCP3PD & A2 & A1B & RCP3PD & A2 & A1B & RCP3PD & L/R & $\begin{array}{l}\text { Prob. } \\
\text { length }\end{array}$ & Clade \\
\hline B. hortorum & $\mathbf{2 0 3 5}$ & $\mathbf{2 0 3 5}$ & $\mathbf{2 0 3 5}$ & $\mathbf{2 0 6 0}$ & $\mathbf{2 0 6 0}$ & $\mathbf{2 0 6 0}$ & $\mathbf{2 0 8 5}$ & $\mathbf{2 0 8 5}$ & $\mathbf{2 0 8 5}$ & & Megabombus \\
B. humilis & 113.5 & 114.5 & 114.2 & 118.3 & 118.6 & 116.1 & 117.3 & 117.9 & 116.5 & $\mathrm{~L}$ & 5 & M \\
B. hypnorum & 206.4 & 221.2 & 213.2 & 331.8 & 336.3 & 246.4 & 443.2 & 415.0 & 253.0 & $\mathrm{R}$ & 2 & Pyrobombus \\
B. lapidarius & 111.1 & 112.3 & 111.7 & 118.5 & 118.7 & 113.9 & 125.7 & 123.6 & 114.3 & $\mathrm{R}$ & 3 & Melanobombus \\
B. mendax & 50.5 & 45.8 & 48.1 & 22.4 & 21.6 & 39.3 & 7.9 & 11.0 & 37.2 & - & 3 & Mendacibombus \\
B. mesomelas & 59.9 & 55.4 & 57.6 & 26.6 & 25.5 & 48.4 & 7.6 & 11.3 & 46.5 & $\mathrm{~L}$ & 4 & Rhodobombus \\
B. monticola & 64.1 & 60.5 & 62.1 & 39.9 & 39.4 & 55.2 & 21.7 & 27.3 & 53.7 & $\mathrm{R}$ & 2 & Pyrobombus \\
B. mucidus & 57.9 & 53.5 & 55.7 & 30.0 & 29.1 & 47.0 & 14.8 & 17.9 & 45.4 & $\mathrm{~L}$ & 2 & Mucidobombus \\
B. pascuorum & 134.3 & 137.5 & 135.9 & 151.0 & 151.4 & 141.8 & 154.0 & 154.3 & 142.8 & $\mathrm{~L}$ & 4 & Thoracobombus \\
B. pratorum & 108.5 & 109.1 & 108.8 & 112.3 & 112.4 & 109.9 & 117.5 & 115.8 & 110.1 & $\mathrm{R}$ & 2 & Pyrobombus \\
B. pyrenaeus & 41.9 & 37.1 & 39.5 & 15.7 & 15.0 & 30.6 & 3.8 & 6.4 & 29.0 & $\mathrm{R}$ & 1 & Pyrobombus \\
B. ruderarius & 92.3 & 90.2 & 91.4 & 74.9 & 74.1 & 86.9 & 53.4 & 60.5 & 85.9 & $\mathrm{~L}$ & 4 & Thoracobombus \\
B. sichelii & 54.0 & 48.7 & 51.3 & 23.4 & 22.4 & 41.5 & 6.3 & 9.8 & 39.8 & $\mathrm{R}$ & 1 & Melanobombus \\
B. soroeensis & 92.8 & 90.9 & 91.7 & 75.0 & 73.9 & 88.1 & 55.5 & 59.2 & 87.2 & - & 2 & Kallobombus \\
B. wurfleinii & 78.9 & 76.0 & 77.5 & 59.1 & 58.2 & 72.2 & 36.6 & 39.7 & 71.1 & R & 3 & Alpigenobombus \\
\hline
\end{tabular}

The L/R column refers to the short- or long-tongued clade (see [37] for more information) The prob. length show the proboscis length score (five categories, see "Methods" and [37] for more information). The last column shows the subgenus clades. 


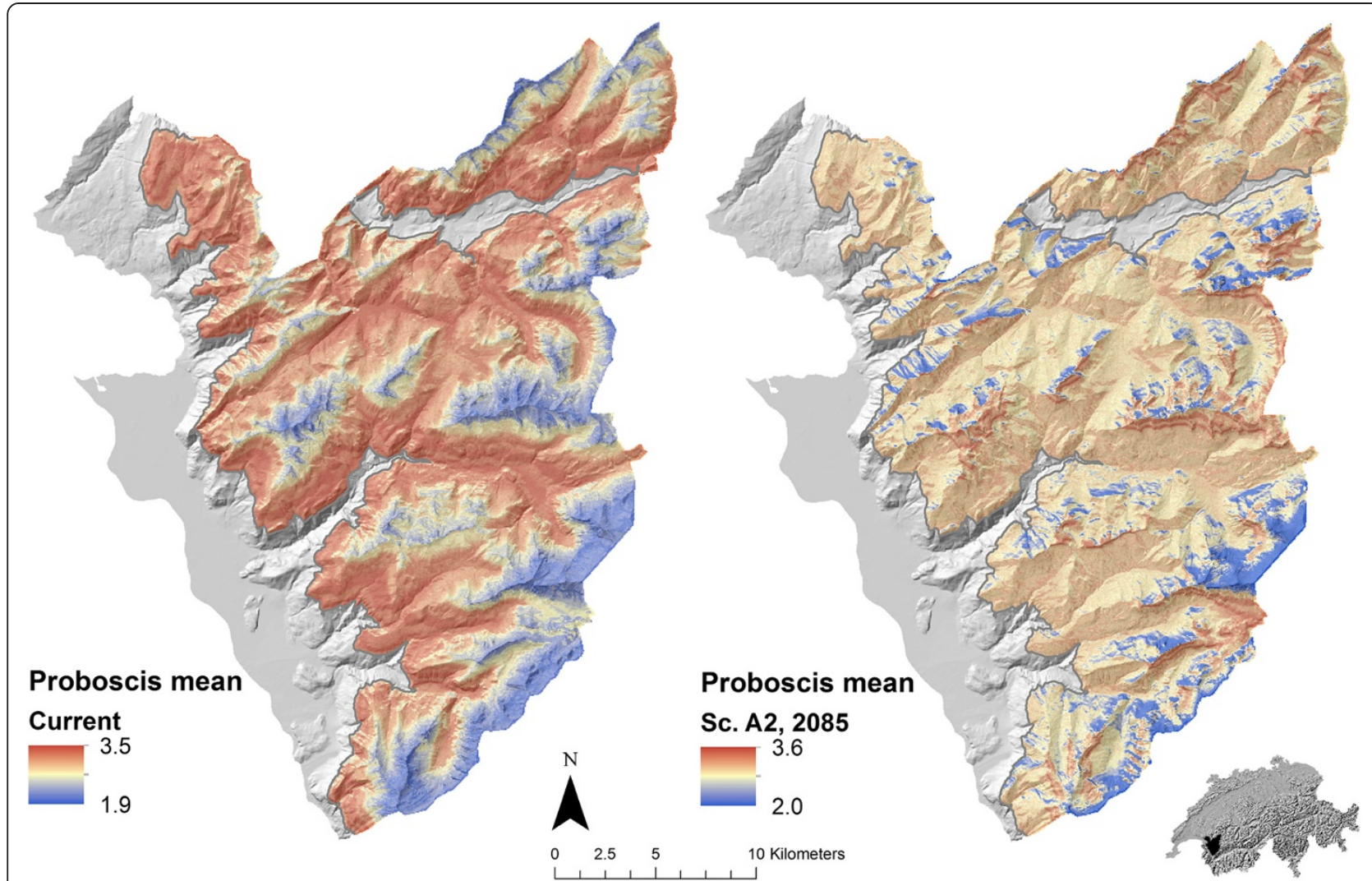

Figure 2 Current and future (scenario A2, period 2085) proboscis mean obtained after the $\mathbf{2 5 0}$ draws. The blue shows low mean proboscis length score whereas the red shows high mean proboscis length score. The grey line shows the 1,000 $\mathrm{m}$ isoline.

species included in the study was predicted to become extinct by 2085 . However, as warming is expected to continue increasing beyond the time frame considered in this study, this ongoing range contraction may lead to the local disappearance of cold-adapted bumblebee species. In addition, we only considered more frequent species ( $>15$ occurrences). It is likely that the rarest species with highly specialized niche will suffer the greatest loss. In particular, B. alpinus was only found in two sites above $2,500 \mathrm{~m}$. The habitat of those already rare species is likely to shrink under climate change. Altogether, species forecasts are in accordance, with observed trend of expansion for some bumblebee species [49] and decrease in others [34], and suggest a species-specific response to climate change.

\section{Homogenization of proboscis diversity under climate change along elevation}

Plant-pollinator networks are strongly modulated by functional traits [24]. The variation in proboscis length of the different pollinator species mediates pollination networks and climate change may remodulate how plants and pollinators interact with each other $[35,48]$. In addition to abiotic filtering, pollination filtering as proposed by Sargent and Ackerly [50] was suggested to currently exclude plant species from high elevation and maintain a pollinationgeneralist flora at high elevation [51]. However, climate change may remove such limitation. The average proboscis length of bumblebee communities decreases with elevation, because species from the long-tongued clade of bumblebees are overall less tolerant to low temperatures and thus restricted to lower elevation [37]. In contrast, bumblebee communities at high elevation are overall composed of species with shorter proboscides that are less able to forage flowers with long spurs [37]. The same pattern was also recorded for plant species where it has been shown that simple actinomorphic flowers were more frequent at higher elevation [52]. Our results suggest that the bumblebee species now occurring at lower elevation and having longer proboscides will track climate change and reach the current alpine landscape and increase the diversity of pollination service. In turn, this functional shift of pollinator assemblages may facilitate the establishment of plant species with more specialized pollination types, which are currently restricted to lower elevation [51].

\section{Caveats of the current modeling approach}

Pollinators influence plant species distribution and community assembly, but the reverse is also expected. Here, we did not consider the floral resource influence on bumblebee 


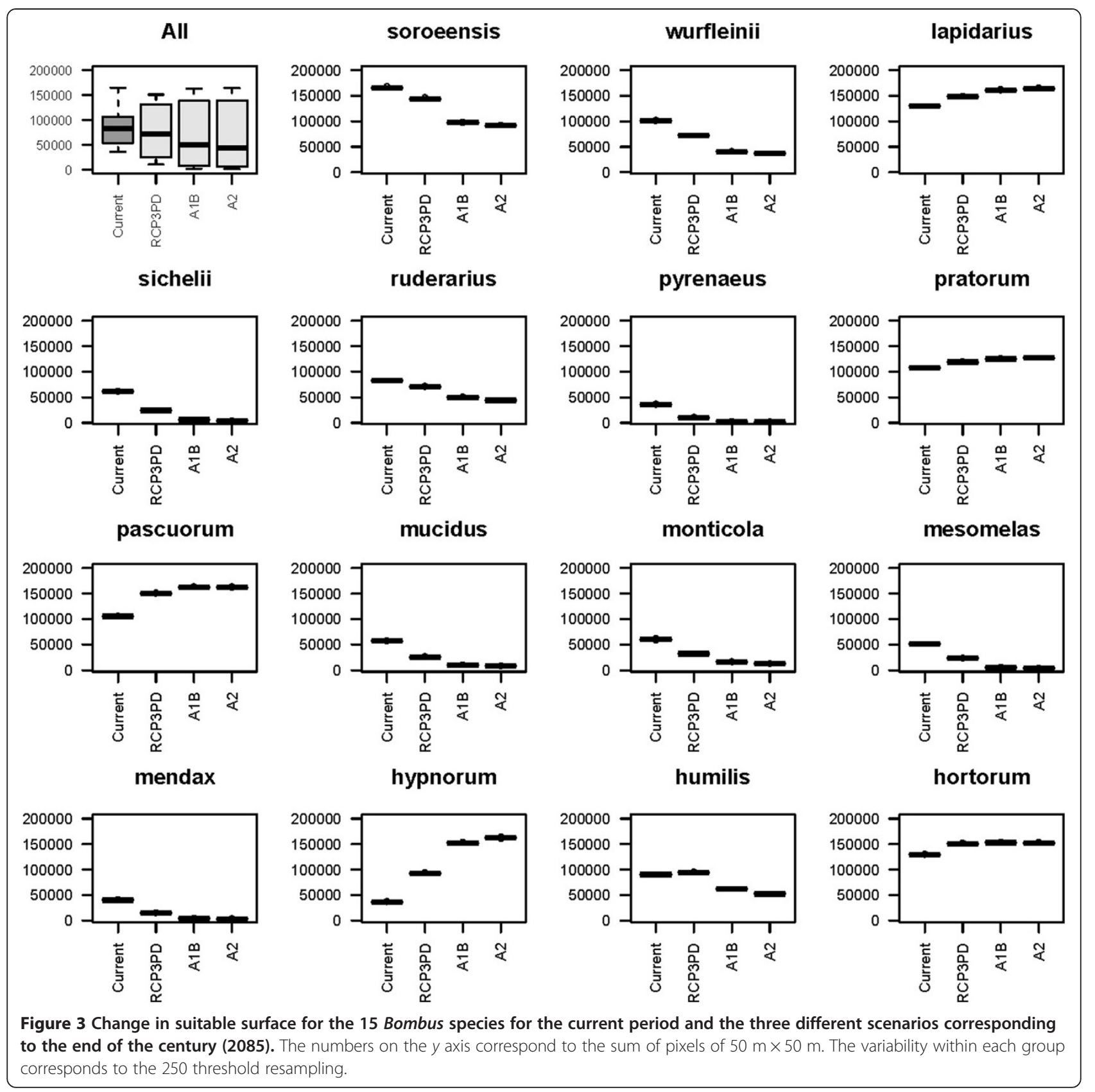

community structure. However, climate change may affect the local survival of bumblebee species in interaction with availability of floral resources. Aldridge et al. [53] showed that climate change may induce longer periods of low flowering abundance in the middle of the summer season that could negatively affect pollinators that are active throughout the season such as bumblebees. In parallel, shifts in flowering peaks within habitats might create mismatches between floral resources and demand by pollinators [53]. In addition, bumblebee species with long proboscides tend to have a more restricted trophic niche compared to species with short proboscides [54]. As a consequence, longtongued bumblebee species may be more sensitive to global change perturbation compared to more generalist species. Using historical data, Dupont et al. [55] showed a consistent and dramatic decline in species richness and abundances of specialized bumblebees (with long proboscis) throughout the flowering season of red clover, while shorttongued species were largely unaffected. Future models should account for feedback processes between plants and pollinators under climate change. Finally, the potentially impact of climate changes and especially weather means 


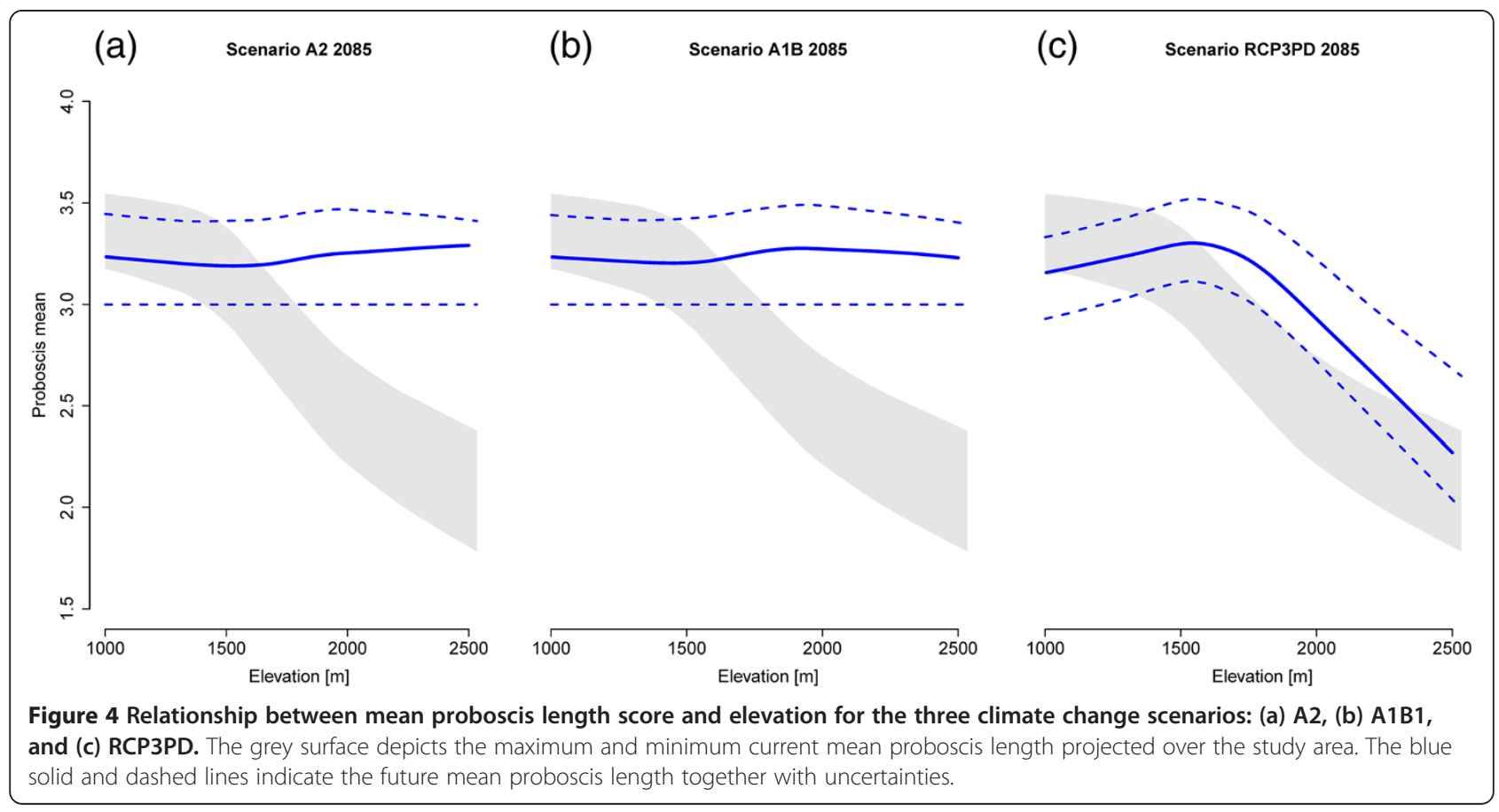

and extremes could lead to individualistic responses which are very hard to predict as demonstrated with alpine butterflies [56].

\section{Conclusions}

Climate change may affect species distribution and community composition either directly through abiotic tolerances to environmental conditions or because of change in biotic interactions. Here, we show that in addition to causing the decrease of several bumblebee species, climate change likely affects the functional structure of communities. In turn, this may impact plant pollination network along elevation under warmer climate. Here, we investigated the potential effect of climate change on pollination as one example of biotic interactions, but further studies are required to investigate other types of biotic interactions and achieve an ecosystem-wide assessment of climate change impacts.

\section{Methods}

\section{Study area and species sampling}

The study area is located in the western Swiss Alps, at elevations ranging from 1,000 to $3,210 \mathrm{~m}$ above sea level, with temperate vegetation belts, i.e., montane, subalpine, alpine, and nival. Lowland sites (below 1,000 m) have not been sampled as they are mostly forested and intensively cultivated areas with a strong human influence on the plants and insect communities. The sampling plot selection was made following a balanced randomstratified sampling design, based on elevation, slope, and aspect, and considering only regions outside of forested areas [57]. During the months of June to September in 2009 and 2010, 149 bumblebee communities were sampled. Sites were visited every 3 weeks during hours of high bumblebee activity (10:00-17:00) and only under good weather conditions (i.e., little wind, sunny, and temperatures above $15^{\circ} \mathrm{C}$ ). Visiting the site several times allows a robust sampling of the communities independently of the phenology. Each site was visited for $45 \mathrm{~min}$, during which bumblebees were sampled in a $50 \mathrm{~m} \times 50 \mathrm{~m}$ area. During the summers 2009 and 2010, we sampled and identified 2,020 individuals. Among these, we found 28 species. We considered only the non-parasitic species that produces colonies and whose worker greatly contributed to plant pollination. We also excluded species with less than 15 occurrences. We ranked the species according to proboscis length as in Pellissier et al. [37]: 1, very short proboscis $(6.5-7.25 \mathrm{~mm}) ; 2$, short proboscis $(7.25-8 \mathrm{~mm})$; 3 , medium proboscis $(8-8.75 \mathrm{~mm})$; 4, long proboscis $(8.75-9.5 \mathrm{~mm})$; and 5 , very long proboscis $(9.5 \mathrm{~mm}$ and above).

\section{Environmental variables}

Recent studies have highlighted the need to produce more accurate thermal predictors to model the distribution of mountain flora and small fauna [58,59]. Using the same approach as Zimmermann and Kienast [60], we modeled temperature at a resolution of $25 \mathrm{~m}$ from 188 temperature stations in Switzerland. We calculated the mean temperature for each month of the growing season (June to August) from 1981 to 2009 according to monthly lapse rates. Using the digital elevation model and the 
monthly lapse rates, we then projected the mean monthly temperatures for the whole study area. We assessed the local variation, adding the residuals interpolated over the study area and thus decoupling partly the temperature from elevation. The 1981-2009 period corresponds to the new reference period used by the Center for Climate System Modeling (http://www.c2sm.ethz.ch/) and is related to new regional climatic warming scenarios. We calculated the amount of solar radiation received in each month of the growing season (June, July, and August) in each pixel with the spatial analyst tool in ArcGIS 10 [61]. To fit the climatic layers with the sampling sites, we aggregated the temperature layers at a resolution of $50 \mathrm{~m}$ using an averaging function before extracting the data corresponding to each sampling point.

\section{Climate change scenario}

We used three different climate projection scenarios (A2, A1B, RCP3PD) averaged for three different models coupling regional and global climatic models (ARPEGEALADIN, ECHAM5-REMO, HadCM3Q0-CLM) using three averaged time periods (2021-2050, 2045-2074, 2070-2099) developed in the Swiss Climate Change Scenario CH2011 project from the Center for Climate Systems Modeling (http://www.c2sm.ethz.ch/). The Swiss Climate Change Scenarios CH2011 provide state-of-the-art projections of how climate may change over the 21st century. They are based on new generations of climate models with higher resolution combining global climate models (e.g., ECHAM5) and regional climate models (REMO). They also provide anomalies for every weather station in Switzerland [62]. These anomalies have been interpolated following the same techniques used for temperature and added to the actual maps. We used a total of 188 temperature stations for the interpolations of the anomalies.

\section{Community modeling}

We modeled individually the species distributions using presence and absence data with two variables: temperature average and solar radiations. We used three different modeling techniques implemented in the biomod2 package [44] and following Engler et al. [8]: a generalized linear model (GLM, [63]), a generalized additive model (GAM, [64]), and a random forest model (RF). For each technique, we used the default settings in bio$\bmod 2$, as these were optimized for SDMs [44]. We randomly split the dataset into 20 partitions, successively calibrating the models using $80 \%$ of the data and sequentially predicting the species distribution and communities based on the remaining $20 \%$ of the data. We measured the SDM predictive power for each species as the AUC of a ROC [65] using a 20-fold split sample procedure (modeling on $80 \%$ of the data, predicting on
$20 \%)$. We applied an ensemble forecasting framework by averaging all single model projections, by AUC [66]. To build prediction, we used an the ensemble forecasting method from the biomod2 package, keeping only the models with AUC values above 0.7 and averaging the remaining models [44].

We used the probabilities predicted by SDMs as actual probabilities following Pellissier et al. [41]. Species may display different tolerances to environmental conditions while still governed by stochastic processes. To obtain predictions of species distributions as binary presence or absence from the species probabilities of occurrence, we used the rbinom function in $\mathrm{R}$. This function draws presences and absences from the probabilities out of a binomial distribution, as previously used in Dubuis et al. [67] and Pellissier et al. [41]. We repeated this process 250 times and produced the same number of predicted potential communities.

We projected the community models over the study area in the current period as well as considering the three climate change scenarios and the three time periods. We subsequently applied a mask representing anthropized areas (cities, roads) and forests as a habitat that was not covered by the current sampling. Species were assumed to have unlimited dispersal capabilities, which is a fair assumption considering the bumblebee flight ability. We calculated the number of pixels occupied by each species in the current climate as well as under the nine climate change scenarios for all runs. We computed the ratio between current and future potential surfaces. Finally, we computed the average of all runs to obtain the main tendency. We evaluated whether some lineages were more likely to benefit or lose from climate warming. Based on the projected communities over each pixel of the study area in the current period as well as considering the three climate change scenarios, we measured the proboscis length average in each pixel and for all runs. Proboscis length for each species was obtained from Pellissier et al. [41]. We related the current and future average and variance in proboscis length to the elevation gradient to evaluate the effect of climate change on the bumblebee functional structure from lowland to the alpine belt.

\section{Additional file}

Additional file 1: Figure S1. Relationship between variance in proboscis length and elevation for the three climate change scenarios: (a) A2, (b) A1B1, and (c) RCP3PD. The grey surface depicts the maximum and minimum current variance in proboscis length along elevation. The blue solid and dashed lines indicate the (...) future mean, maximum and minimum variance (...) variance in proboscis length.

\section{Competing interests}

The authors declare that they have no competing interests. 


\section{Authors' contributions}

LP and AG conceived the idea for the study and designed the research. JNP and LP collected the community data. JNP, LP, and CFR carried out the analyses. All authors discussed the results, implications, and wrote the manuscript. All authors read and approved the final manuscript.

\section{Acknowledgements}

We would like to thank the field assistance of Alexander Von Ungern, Virginie Favre, Valéry Udry, Sarah Giovanettina, Vanessa Rion, Christian Purro, and Saskia Godat. This study was supported by the European Commission (ECOCHANGE project, contract nr. FP6 2006 GOCE 036866) and by Swiss National Science Foundation (SNSF) grant Nr. 31003A-125145 (BIOASSEMBLE project) accorded to AG. LP was supported by the Danish Council for Independent Research grant no. 12-126430 and the grant "Félix Bonjour" of the Société Académique Vaudoise.

\section{Author details}

'Department of Ecology and Evolution, University of Lausanne, Bâtiment Biophore, CH-1015 Lausanne, Switzerland. ²Department of Biology Ecology \& Evolution, University of Fribourg, $\mathrm{CH}-1700$ Fribourg, Switzerland. ${ }^{3}$ Botanisches Institut der Universität Basel, Schönbeinstrasse 6, 4056 Basel, Switzerland. ${ }^{4}$ Institute of Earth Surface Dynamics, University of Lausanne, CH-1015 Lausanne, Switzerland.

Received: 6 February 2014 Accepted: 3 June 2014

Published online: 22 October 2014

\section{References}

1. Parmesan C: Ecological and evolutionary responses to recent climate change. Annu Rev Ecol Evol Syst 2006, 37:637-669.

2. Bellard C, Bertelsmeier C, Leadley P, Thuiller W, Courchamp F: Impacts of climate change on the future of biodiversity. Ecol Lett 2012:365-377.

3. Van der Putten WH, Macel M, Visser ME: Predicting species distribution and abundance responses to climate change: why it is essential to include biotic interactions across trophic levels. Philos Trans $R$ Soc Lond B Biol Sci 2010, 365:2025-2034.

4. Schweiger O, Settele J, Kudrna O, Klotz S, Kühn I: Climate change can cause spatial mismatch of trophically interacting species. Ecology 2008, 89:3472-3479.

5. Bartomeus I, Ascher JS, Wagner D, Danforth BN, Colla S, Kornbluth S, Winfree R: Climate-associated phenological advances in bee pollinators and bee-pollinated plants. Proc Natl Acad Sci U S A 2011, 108:20645-20649.

6. Dunne JA, Williams RJ: Cascading extinctions and community collapse in model food webs. Philos Trans R Soc Lond B Biol Sci 2009, 364:1711-1723.

7. Walther G-R: Community and ecosystem responses to recent climate change. Philos Trans R Soc Lond B Biol Sci 2010, 365:2019-2024.

8. Engler R, Randin CF, Thuiller W, Dullinger S, Zimmermann NE, Araújo MB, Pearman PB, Le Lay G, Piedallu C, Albert CH, Choler P, Coldea G, De Lamo X, Dirnböck T, Gégout J, Gómez-García D, Grytnes J-A, Heegaard E, Høistad F, Nogués-Bravo D, Normand S, Puşcaş M, Sebastià M-T, Stanisci A, Theurillat J-P, Trivedi MR, Vittoz P, Guisan A: 21st century climate change threatens mountain flora unequally across Europe. Glob Chang Biol 2011, $17: 2330-2341$

9. Wisz MS, Pottier J, Kissling WD, Pellissier L, Lenoir J, Damgaard CF, Dormann CF, Forchhammer MC, Grytnes J-A, Guisan A, Heikkinen RK, Høye TT, Kühn I, Luoto M, Maiorano L, Nilsson M-C, Normand S, Öckinger E, Schmidt NM, Termansen M, Timmermann A, Wardle DA, Aastrup P, Svenning J-C: The role of biotic interactions in shaping distributions and realised assemblages of species: implications for species distribution modelling. Biol Rev Camb Philos Soc 2013, 88:15-30.

10. Tylianakis JM, Didham RK, Bascompte J, Wardle DA: Global change and species interactions in terrestrial ecosystems. Ecol Lett 2008, 11:1351-1363.

11. Dubuis A, Giovanettina S, Pellissier L, Pottier J, Vittoz P, Guisan A: Improving the prediction of plant species distribution and community composition by adding edaphic to topo-climatic variables. J Veg Sci 2013, 24:593-606.

12. Kremen C, Ostfeld RS: A call to ecologists: measuring, analyzing, and managing ecosystem services. Front Ecol Environ 2005, 3:540.

13. Waser NM, Chittka L, Price MV, Williams NM, Ollerton J: Generalization in pollination systems, and why it matters. Ecology 1996, 77:1043-1060.
14. Blüthgen $\mathrm{N}$, Klein A-M: Functional complementarity and specialisation: the role of biodiversity in plant-pollinator interactions. Basic App/ Ecol 2011, 12:282-291.

15. Lenoir J, Gégout JC, Marquet PA, de Ruffray P, Brisse HMarquet PA, de Ruffray $P$, Brisse $H$ : A significant upward shift in plant species optimum elevation during the 20th century. Science 2008, 320:1768-1771.

16. Parmesan C: Climate and species' range. Nature 1996, 382:765-766.

17. Chen I-C, Hill JK, Ohlemüller R, Roy DB, Thomas CD: Rapid range shifts of species associated with high levels of climate warming. Science 2011, 333:1024-1026.

18. Pöry J, Luoto M, Heikkinen RK, Kuussaari M, Saarinen K: Species traits explain recent range shifts of Finnish butterflies. Glob Chang Biol 2009, 15:732-743

19. Angert AL, Crozier LG, Rissler LJ, Gilman SE, Tewksbury JJ, Chunco AJ: Do species' traits predict recent shifts at expanding range edges? Ecol Lett 2011, 14:677-689.

20. Kuhlmann M, Guo D, Veldtman R, Donaldson J: Consequences of warming up a hotspot: species range shifts within a centre of bee diversity. Divers Distrib 2012, 18:885-897.

21. Araújo MB, Luoto M: The importance of biotic interactions for modelling species distributions under climate change. Glob Ecol Biogeogr 2007, 16:743-753

22. Bassin L, Alvarez N, Pellissier L, Triponez Y: Ecological niche overlap in sister species: how do oil-collecting bees Macropis europaea and Macropis fulvipes (Hymenoptera: Melittidae) avoid hybridization and competition? Apidologie 2011, 42:579-595.

23. Bond W: Do mutualisms matter? Assessing the impact of pollinator and disperser disruption on plant extinction. Philos Trans R Soc Lond B Biol SC 1994, 344:83-90.

24. Corbet SA: Conserving compartments in pollination webs. Conserv Biol 2000, 14:1229-1231.

25. Fontaine C, Dajoz I, Meriguet J, Loreau M: Functional diversity of plant-pollinator interaction webs enhances the persistence of plant communities. PLoS Biol 2006, 4:e1.

26. Pellissier L, Pottier J, Vittoz P, Dubuis A, Guisan A: Spatial pattern of floral morphology: possible insight into the effects of pollinators on plant distributions. Oikos 2010, 119:1805-1813.

27. Pellissier L, Alvarez N, Guisan A: Pollinators as drivers of plant distribution and assemblage into communities. In Evolution of Plant-Pollinator Relationships. Systematics Association Special Volume Series. Edited by Patiny S. Cambridge: Cambridge University Press; 2011:392-413. Available from: Cambridge Books Online [http://dx.doi.org/10.1017/CBO9781139014113.015]

28. Lavorel S, McIntyre S, Landsberg J, Forbes T: Plant functional classifications: from general groups to specific groups based on response to disturbance. Trends Ecol Evol 1997, 12:474-478.

29. Beniston M, Rebetez M: Regional behavior of minimum temperatures in Switzerland for the period 1979-1993. Theor App/ Climatol 1996, 53:231-243.

30. Xu J, Grumbine RE, Shrestha A, Eriksson M, Yang X, Wang Y, Wilkes A: The melting Himalayas: cascading effects of climate change on water, biodiversity, and livelihoods. Conserv Biol 2009, 23:520-530.

31. Bingham RA, Ranker TA: Genetic diversity in alpine and foothill populations of Campanula rotundifolia (Campanulaceae). Int J Plant Sci 2000, 161:403-411.

32. Heinrich B: Thermoregulation in bumblebees. Biomed Life Sci 1975, 96:155-166.

33. Osborne JL, Clark SJ, Morris RJ, Williams IH, Riley JR, Smith AD, Reynolds DR, Edwards AS: A landscape-scale study of bumble bee foraging range and constancy, using harmonic radar. J Appl Ecol 1999, 36:519-533.

34. Cameron SA, Lozier JD, Strange JP, Koch JB, Cordes N, Solter LF, Griswold TL: Patterns of widespread decline in North American bumble bees. Proc Natl Acad Sci U S A 2011, 108:662-667.

35. Hegland SJ, Nielsen A, Lázaro A, Bjerknes A-L, Totland Ø: How does climate warming affect plant-pollinator interactions? Ecol Lett 2009, 12:184-195.

36. Fussell M, Corbet SA: Flower usage by bumble-bees: a basis for forage plant management. J Appl Ecol 1992, 29:451.

37. Pellissier L, Pradervand J-N, Williams PH, Litsios G, Cherix D, Guisan A: Phylogenetic relatedness and proboscis length contribute to structuring bumblebee communities in the extremes of abiotic and biotic gradients. Glob Ecol Biogeogr 2012.

38. Guisan A, Thuiller W: Predicting species distribution: offering more than simple habitat models. Ecol Lett 2005, 8:993-1009. 
39. Guisan A, Rahbek C: SESAM - a new framework integrating macroecological and species distribution models for predicting spatio-temporal patterns of species assemblages. J Biogeogr 2011, 38:1433-1444.

40. Pottier J, Dubuis A, Pellissier L, Maiorano L, Rossier L, Randin CF, Vittoz P, Guisan A: The accuracy of plant assemblage prediction from species distribution models varies along environmental gradients. Glob Ecol Biogeogr 2013, 22:52-63.

41. Pellissier L, Espíndola A, Pradervand J-N, Dubuis A, Pottier J, Ferrier S, Guisan A: A probabilistic approach to niche-based community models for spatial forecasts of assemblage properties and their uncertainties. J Biogeogr 2013, 40:1939-1946.

42. Elith J, Graham CH, Anderson RP, Dudík M, Ferrier S, Guisan A, Hijmans RJ, Huettmann F, Leathwick JR, Lehmann A, Li J, Lohmann LG, Loiselle BA Manion G, Moritz C, Nakamura M, Nakazawa Y, McC Overton J, Townsend Peterson A, Phillips SJ, Richardson K, Scachetti-Pereira R, Schapire RE, Soberón J, Williams S, Wisz MS, Zimmermann NE: Novel methods improve prediction of species' distributions from occurrence data. Ecography (Cop) 2006, 29:129-151.

43. Wolf $\mathrm{S}$, Rohde M, Moritz RFA: The reliability of morphological traits in the differentiation of Bombus terrestris and B. lucorum (Hymenoptera: Apidae). Apidologie 2009, 41:45-53.

44. Thuiller W, Georges D, Engler R: biomod2: ensemble platform for species distribution modeling. 2013. R package version 3.1-18 [http://CRAN.R-project.org]

45. Owen EL, Bale JS, Hayward SAL: Can winter-active bumblebees survive the cold? Assessing the cold tolerance of Bombus terrestris audax and the effects of pollen feeding. PLoS One 2013, 8:e80061.

46. Goulson D, Hanley ME, Darvill B, Ellis JS, Knight ME: Causes of rarity in bumblebees. Biol Conserv 2005, 122:1-8.

47. Macdonald M: The colonisation of Northern Scotland by Bombus terrestris (L.) and B. lapidarius (L.) (Hym., Apidae), and the possible role of climate change. Entomol Mon Mag 2001, 137:1-14.

48. Schweiger O, Biesmeijer JC, Bommarco R, Hickler T, Hulme PE, Klotz S, Kühn I, Moora M, Nielsen A, Ohlemüller R, Petanidou T, Potts SG, Pyšek P, Stout JC, Sykes MT, Tscheulin T, Vilà M, Walther G-R, Westphal C, Winter M, Zobel M, Settele J: Multiple stressors on biotic interactions: how climate change and alien species interact to affect pollination. Biol Rev Camb Philos Soc 2010, 85:777-795.

49. Owen RE, Otterstatter MC, Cartar RV, Farmer A, Colla SR, OToole N: Significant expansion of the distribution of the bumble bee Bombus moderatus (Hymenoptera: Apidae) in Alberta over 20 years. Can J Zool 2012, 90:133-138.

50. Sargent RD, Ackerly DD: Plant-pollinator interactions and the assembly of plant communities. Trends Ecol Evol 2008, 23:123-130.

51. Pellissier L, Litsios G, Fiedler K, Pottier J, Dubuis A, Pradervand J-N, Salamin N, Guisan A: Loss of interactions with ants under cold climate in a regional myrmecophilous butterfly fauna. J Biogeogr 2012, 39:1782-1790.

52. Herrera J: Flower size variation in Rosmarinus officinalis: individuals, populations and habitats. Ann Bot 2005, 95:431-437.

53. Aldridge G, Inouye DW, Forrest JRK, Barr WA, Miller-Rushing AJ: Emergence of a mid-season period of low floral resources in a montane meadow ecosystem associated with climate change. J Ecol 2011, 99:905-913.

54. Goulson D: Bumblebees: Behaviour, Ecology, and Conservation. Oxford: Oxford Univ Press; 2010.

55. Dupont $Y L$, Damgaard C, Simonsen V: Quantitative historical change in bumblebee (Bombus spp.) assemblages of red clover fields. PLOS One 2011, 6:e25172.

56. Buckley LB, Kingsolver JG: The demographic impacts of shifts in climate means and extremes on alpine butterflies. Funct Ecol 2012, 26:969-977.

57. Hirzel A, Guisan A: Which is the optimal sampling strategy for habitat suitability modelling. Ecol Modell 2002, 157:331-341.

58. Austin MP, Van Niel KP: Improving species distribution models for climate change studies: variable selection and scale. J Biogeogr 2011, 38:1-8.

59. Graae BJ, De Frenne P, Kolb A, Brunet J, Chabrerie O, Verheyen K, Pepin N, Heinken T, Zobel M, Shevtsova A, Nijs I, Milbau A: On the use of weather data in ecological studies along altitudinal and latitudinal gradients. Oikos 2012, 121:3-19.

60. Zimmermann N, Kienast F, Niklaus E: Predictive mapping of alpine grasslands in Switzerland: species versus community approach. J Veg Sci 1999, 10:469-482.

61. ESRI: ArcG/S Desktop: Release 10. Redlands, CA: Environmental Systems Research Institute; 2012.
62. Bosshard T, Kotlarski S, Ewen T, Schär C: Spectral representation of the annual cycle in the climate change signal. Hydrol Earth Syst Sci 2011, $15: 2777-2788$

63. McCullagh P, Nelder JA: Generalized Linear Models. Chapman \& Hall/CRC 1989.

64. Hastie T, Tibshirani R: Generalized additive models. Stat Sci 1990, 1:297-318

65. Swets J: Measuring the accuracy of diagnostic systems. Science 1988, 240:1285-1293.

66. Araújo MB, New M: Ensemble forecasting of species distributions. Trends Ecol Evol 2007, 22:42-47.

67. Dubuis A, Pottier J, Rion V, Pellissier L, Theurillat J-P, Guisan A: Predicting spatial patterns of plant species richness: a comparison of direct macroecological and species stacking modelling approaches. Divers Distrib 2011, 17:1122-1131.

doi:10.1186/s40665-014-0001-5

Cite this article as: Pradervand et al: Functional homogenization of bumblebee communities in alpine landscapes under projected climate change. Climate Change Responses 2014 1:1.

\section{Submit your next manuscript to BioMed Central and take full advantage of:}

- Convenient online submission

- Thorough peer review

- No space constraints or color figure charges

- Immediate publication on acceptance

- Inclusion in PubMed, CAS, Scopus and Google Scholar

- Research which is freely available for redistribution

Submit your manuscript at www.biomedcentral.com/submit
C Biomed Central 